\title{
Small dose of naloxone as an adjuvant to bupivacaine in intrapleural infiltration after thoracotomy surgery: a prospective, controlled study
}

\author{
Asmaa Fawzy Amer and Amany Faheem Omara
}

Department of Anesthesiology, Surgical Intensive Care and Pain Medicine, Faculty of Medicine, Tanta University, Tanta, Egypt

Background: Severe pain always develops after thoracotomy; intrapleural regional analgesia is used as a simple, safe technique to control it. This study was performed to evaluate whether a small dose of naloxone with local anesthetics prolongs sensory blockade.

Methods: A prospective, randomized double-blinded controlled study was conducted on 60 patients of American Society of Anesthesiologists statuses I and II, aged 18 to 60 years, scheduled for unilateral thoracotomy surgery. After surgery, patients were randomly divided into two groups: through the intrapleural catheter, group B received $30 \mathrm{ml}$ of $0.5 \%$ bupivacaine, while group $\mathrm{N}$ received $30 \mathrm{ml}$ of $0.5 \%$ bupivacaine with $100 \mathrm{ng}$ of naloxone. Postoperative pain was assessed using the visual analog pain scale (VAS). Time for the first request for rescue analgesia, total amount consumed, and incidence of postoperative complications were also recorded.

Results: The VAS score significantly decreased in group $\mathrm{N}$, at $6 \mathrm{~h}$ and $8 \mathrm{~h}$ after operation $(P<0.001$ for both). At $12 \mathrm{~h}$ after injection, the VAS score increased significantly in group $\mathrm{N}(P<0.001)$. The time for the first request of rescue analgesia was significantly longer in group $\mathrm{N}$ compared to group $\mathrm{B}(P<0.001)$. The total amount of morphine consumed was significantly lower in group $\mathrm{N}$ than in the bupivacaine group $(P<0.001)$.

Conclusions: Addition of a small dose of naloxone to bupivacaine in intrapleural regional analgesia significantly prolonged pain relief after thoracotomy and delayed the first request for rescue analgesia, without significant adverse effects. (Korean J Pain 2019; 32: 105-12)

Key Words: Analgesia; Anesthetics, local; Bupivacaine; Incidence; Intrapleural analgesia; Naloxone; Pain measurement; Pain, postoperative; Thoracotomy.

Received November 26, 2018. Revised February 2, 2019. Accepted February 3, 2019.

Correspondence to: Amany Faheem Omara

Department of Anesthesiology, Surgical Intensive Care and Pain Medicine, Faculty of Medicine, Tanta University, 3 Mohamed Faried St, Tanta, Tanta 31527, Egypt

Tel: +20-10-0837-2249, E-mail: amanyfaheem2011@yahoo.com

ORCID: https://orcid.org/0000-0002-9025-632X

(C) This is an open-access article distributed under the terms of the Creative Commons Attribution Non-Commercial License (http:// creativecommons.org/licenses/by-nc/4.0/), which permits unrestricted non-commercial use, distribution, and reproduction in any medium, provided the original work is properly cited.

(c) The Korean Pain Society, 2019 


\section{INTRODUCTION}

Severe pain is always felt after thoracotomy [1]. Controlling postoperative pain has been an essential step to decrease the incidence of retention of secretions, atelectasis, and pneumonia, as post-thoracotomy pain decreases patient ability to perform adequate pulmonary hygiene [2].

Systemic narcotics have many side effects, so different regional techniques have been investigated, such as thoracic epidurals, paravertebral blocks, intercostal nerve blocks, and intrapleural (IP) regional analgesia, to relieve pain after thoracotomy, and they were thus recommended [3]. IP regional analgesia is a simple, easy-to-perform technique used to control pain after thoracotomy surgery. In IP, local anesthetic (LA) drugs were injected between the visceral and parietal pleura either as a single bolus or as an infusion via an indwelling catheter [4].

Naloxone, which is known as an opioid antagonist, used to counter the effects of opioid overdose, has been used in low dose as an additive to LA drugs to prolong sensory and motor nerve blocks in supraclavicular brachial plexus blockade and peribulbar anesthesia $[5,6]$.

The present controlled clinical trial evaluated the effect of a small dose of naloxone added to bupivacaine, versus bupivacaine alone, on the duration of IP analgesia after thoracotomy. Our primary outcome is the time until the first request for rescue analgesia, while the secondary outcome is the severity of postoperative pain.

\section{MATERIALS AND METHODS}

After approval of the study by the Tanta Faculty of the Medicine Research Ethics Committee (approval code 32275/04/18), it was registered on the Pan African Clinical Trial Registry (PACTR201805003370384) on April 5, 2018. This prospective controlled randomized double-blind study was conducted at Tanta University Hospitals, starting in May 2018. The research lasted for 6 months. Sixty patients aged 18 to 60 years, of both genders and of American Society of Anesthesiologists statuses I or II, presented for unilateral thoracic surgery (diaphragmatic hernia repair, lymph node excision, decortication, and pneumonectomy), were included in this study.

Preoperative assessment was carried out for all patients by collecting their history, conducting general and local investigations, and requesting analysis of complete blood count, coagulation study, renal, and liver function tests. Informed written consent was obtained from the patients who were accepted to participate in the study, and the patients retained a copy of the document. All the obtained data and results about the participating patients were kept in secrecy in private files.

The hospital pharmacy prepared similar syringes containing bupivacaine alone or bupivacaine plus naloxone, and they were introduced to the participating patients in sealed envelopes by an anesthesia resident who was not participating in this work, ensuring that the patients and the assessors were blind to the technique. Patients who refused to participate in the study; those who had undergone emergency operations; those who underwent thoracotomy in the past; and those with a history of allergy to LAs, previous unusual response or complications related to anesthesia, pre-existing coagulopathy, severe comorbidity, pleuritis, traumatic or spontaneous pneumothorax, hemothorax, pneumonia, or any condition associated with a potential to increase absorption of LAs, as well as cardiac failure, upper airway obstruction, or apneic attacks and local infection, were all excluded from the study.

Before premedication was given, intravascular access was established once the patients were admitted into the operating theater by inserting an 18-gauge peripheral venous cannula, and then an intravenous infusion of $7 \mathrm{ml} / \mathrm{kg}$ lactated ringer solution was carried out. Premedication of all patients was done by administering $0.1 \mathrm{mg} / \mathrm{kg} \mathrm{mid}-$ azolam intravenously $15 \mathrm{~min}$ before induction of anesthesia with oxygenation using a nasal cannula. The patients were closely monitored by pulse oximetry, non-invasive blood pressure measurement, and three-lead electrocardiogram once they were admitted into the operating room.

Anesthesia was induced by injecting $2 \mathrm{mg} / \mathrm{kg}$ propofol and $1 \mathrm{ug} / \mathrm{kg}$ fentanyl intravenously. Endotracheal intubation was facilitated by injecting $0.9 \mathrm{mg} / \mathrm{kg}$ rocuronium bromide intravenously. Anesthesia was maintained using $\mathrm{O}_{2}$ with $2 \%$ sevoflurane to maintain a bispectral index of $40-60$. Neuromuscular relaxation was maintained by intravenously injecting rocuronium top-ups of $0.3 \mathrm{mg}$ every hour. The lungs were mechanically ventilated to keep the end tidal $\mathrm{CO}_{2}$ within $35 \pm 5 \mathrm{mmHg}$. The temperature probe was inserted, and temperature recorded. The patient was catheterized, and urine output was recorded.

At the end of surgery, and before skin closure, the 
surgeon percutaneously inserted a 20 guage catheter using a Tuohy needle (19 guage) between the visceral and parietal layers of the pleura just above the posteromedial aspect of the incision, which was then secured loosely to the parietal pleura in the high paravertebral region of the chest. A sterile dressing was applied at the skin entry site, fitting a bacterial filter to the catheter. The chest tube was placed in the lateral part of the pleural space, and then the 60 patients were randomly distributed to two equal groups (30 patients each). A random allocation of the participating patients was carried out using computer software.

Group B (the bupivacaine group) patients received 30 $\mathrm{ml}$ of $0.5 \%$ bupivacaine injected over $5 \mathrm{~min}$, while clamping the chest tube for $15 \mathrm{~min}$. Group N (the bupivacaine-naloxone group) patients received $30 \mathrm{ml}$ of $0.5 \%$ bupivacaine with $100 \mathrm{ng}$ of naloxone injected over $5 \mathrm{~min}$, while clamping the chest tube for $15 \mathrm{~min}$.

After $15 \mathrm{~min}$, chest tubes were unclamped in both groups and attached to a light suction $\left(10-15 \mathrm{cmH}_{2} \mathrm{O}\right)$, while patients were continuously nursed in a supine position, keeping the operated side on top. At the end of surgery, residual muscle paralysis was reversed, and the trachea was extubated when the extubation criteria was fulfilled. Following extubation and making sure the patients were awake, they were transferred to the intensive care unit. An anteroposterior (AP) chest radiograph was taken upon their arrival, to evaluate the location of the catheter and exclude pneumothorax. AP chest radiograph was repeated the next morning and after catheter removal. Oxygen/air was routinely supplied to all patients during the first few hours based on need. Twenty-four hours later, the IP catheter was removed and the tip sent for bacteriological examination.

During the postoperative period, the visual analog scale (VAS), composed of a 0-10 metric score, was used to evaluate postoperative pain. All patients had been introduced to the VAS at their preoperative visit and were taught how to use it to express the level of pain. The VAS score was estimated immediately after the operation, at 15 min intervals during the first hour and then at 6,12 , 18 , and $24 \mathrm{~h}$ after the LA injection. Whenever the patients had a VAS score $\geq 4$, they were given rescue analgesia in the form of $4 \mathrm{mg}$ morphine and 1,000 mg paracetamol, intravenously, that could be repeated after $6 \mathrm{~h}$. The total dose of morphine and paracetamol consumed and the time of the first request for rescue analgesia after surgery were calculated in the first $24 \mathrm{~h}$. Also, the incidence of other postoperative complications, such as bradypnea, hypoxemia, nausea and vomiting, pruritus, or hypotension, were recorded. Quality of sleep the first night following surgery was assessed using the Consensus Sleep Diary [7], which consists of a self-assessment questionnaire filled out by the patients regarding their sleep experience the night after surgery. After completing the questionnaire, the quality of sleep was determined as very good, good, fair, bad, or very bad.

A pilot study was conducted on ten patients (five from each group, included in the final study) undergoing unilateral thoracotomy. The time for the first request of rescue analgesia was significantly prolonged from $6.7 \pm 0.9 \mathrm{~h}$ to $11 \pm 0.8 \mathrm{~h}$ with naloxone. So, at least 30 patients were required in each group to detect prolongation of the time for the first request for rescue analgesia by $4.3 \mathrm{~h}$ at an $\alpha$ value of 0.05 and $90 \%$ power of the study. The statistically analyzed data were presented as a mean and standard deviation or as a number and percent. Non-parametric data were analyzed by Fisher exact test, while numerical data were analyzed by an unpaired T-test. The Mann-Whitney test was used for the statistical evaluation of the Consensus Sleep Diary. Whenever $P<0.05$, the level was considered significant. A computer program (SPSS ver. 22; SPSS Inc., Chicago, IL) was used for statistical analysis of the collected data.

\section{RESULTS}

A total of 79 patients were thought eligible for this clinical study. However, 19 patients were excluded due to either not meeting the inclusion criteria (from 11 patients, five were diagnosed with pre-existing coagulopathy, three had a history of pleuritis, two had a previous history of thoracotomy, and one was on routine nonsteroidal anti-inflammatory drugs) or refusing to participate (8 patients). The remaining 60 patients were randomly divided into two equal groups. Data from all patients were successfully collected (Fig. 1).

Patients' characteristics, including age, sex, body mass index, and American Society of Anesthesiologists physical status, were found to be comparable between the two groups ( $P=0.1,0.8,0.9$, and 0.6 , respectively). Also, the type of surgery was statistically insignificant between 


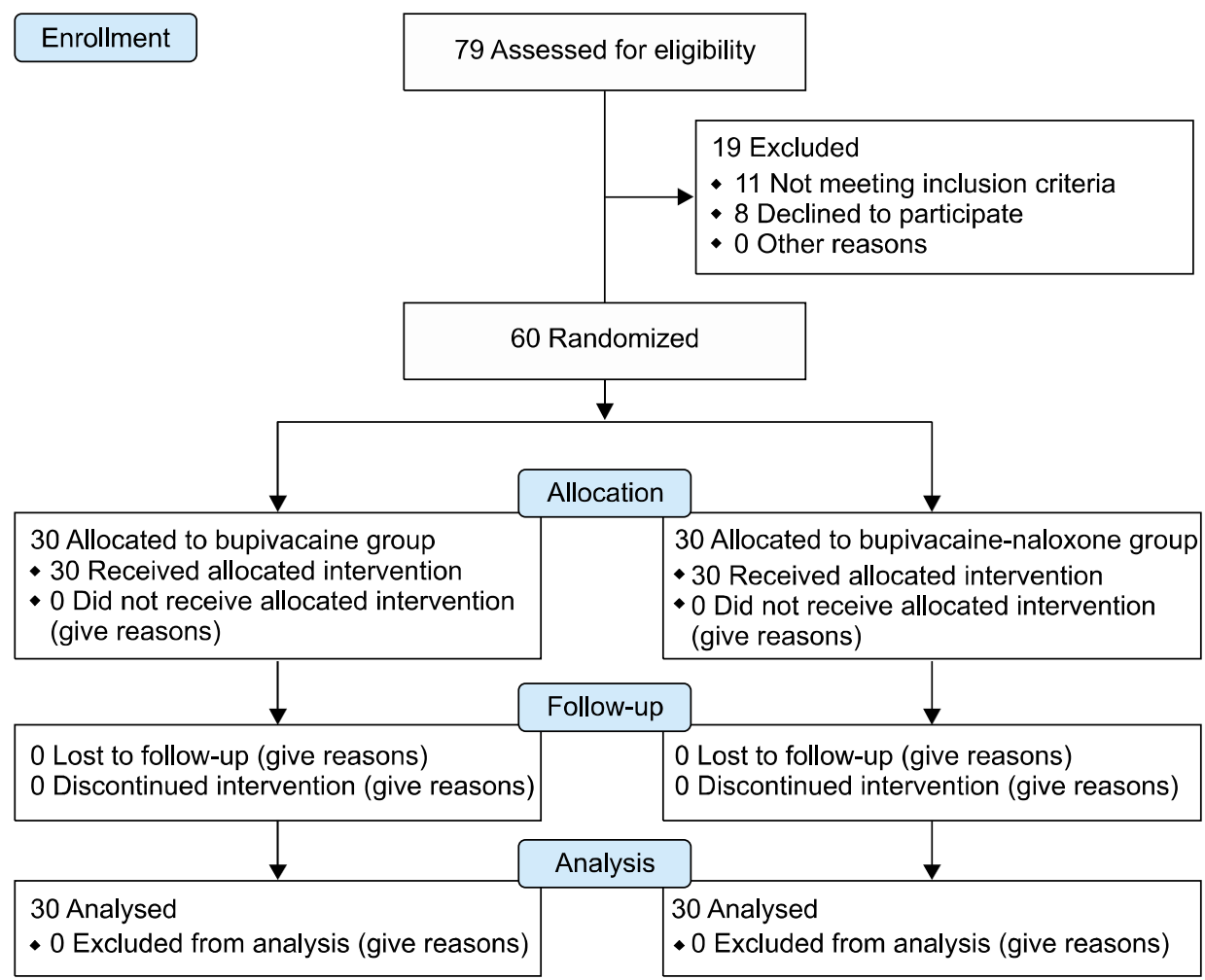

Fig. 1. CONSORT flow chart.

Table 1. Demographic Data, ASA Physical Status, and Type of Surgery

\begin{tabular}{lccc}
\hline \multicolumn{1}{c}{ Demographic data } & $\begin{array}{c}\text { Bupivacaine } \\
(\mathrm{n}=30)\end{array}$ & $\begin{array}{c}\text { Bupivacaine- } \\
\text { naloxone } \\
(\mathrm{n}=30)\end{array}$ & $\begin{array}{c}P \\
\text { value }\end{array}$ \\
\hline Age (y) & $48.4 \pm 1.1$ & $49 \pm 0.8$ & 0.1 \\
Sex (male : female) & $16: 14$ & $15: 15$ & 0.8 \\
Type of surgery & & & 0.9 \\
$\quad$ Diaphragmatic hernia repair & $10(33.3)$ & $11(36.7)$ & \\
Lymph node excision & $9(30.0)$ & $8(26.6)$ & \\
$\quad$ Decortication & $11(36.7)$ & $11(36.7)$ & \\
Body mass index $\left(\mathrm{kg} / \mathrm{m}^{2}\right)$ & $25.4 \pm 1.1$ & $25.4 \pm 1.2$ & 0.9 \\
ASA physical status $(\mathrm{I} / \mathrm{II})$ & $17 / 13$ & $15 / 15$ & 0.6
\end{tabular}

Values are presented as mean \pm standard deviation or number (\%). ASA: American Society of Anesthesiologists.

the groups $(P=0.09)$ (Table 1$)$.

Postoperative pain was assessed immediately after extubation, showing no significant difference between the groups $(P=0.70)$. On the other hand, the VAS score was significantly lower in the naloxone group, $6 \mathrm{~h}$ and $8 \mathrm{~h}$ after operation, than the bupivacaine group $(P<0.001$ for both). At $12 \mathrm{~h}$ after injection, the VAS score significantly

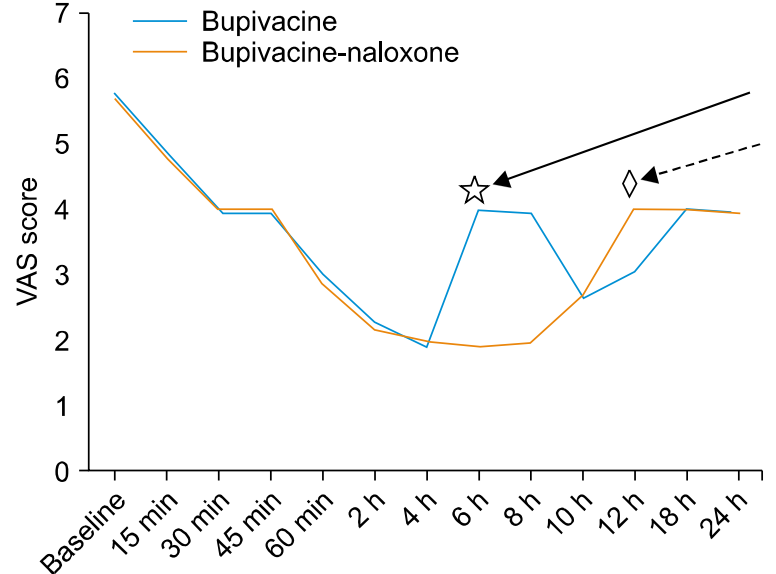

Fig. 2. The severity of postoperative pain and onset of analgesia. Interrupted arrow pointed to the time at which visual analogue scale (VAS) significantly increases in naloxone group than bupivacaine group ( $12 \mathrm{~h}$ marked by $\diamond)$. Continuous arrow pointed to the time at which VAS significantly increases in bupivacaine group than naloxone group ( $6 \mathrm{~h}$ marked by 3 ).

increased in the naloxone group in comparison to the other group $(P<0.001)$. Both groups at 15 minutes, $30 \mathrm{~min}$, $45 \mathrm{~min}, 60 \mathrm{~min}, 2 \mathrm{~h}, 4 \mathrm{~h}, 10 \mathrm{~h}, 18 \mathrm{~h}$, and $24 \mathrm{~h}$ after the 
operation were non-significantly different $(P=0.6,1,0.7$, $0.5,0.5,0.6,1,1$, and 1, respectively) (Fig. 2).

Time for the first request of rescue analgesia was significantly longer in the naloxone group (11 \pm 0.8 hours) compared to the bupivacaine group $(6.7 \pm 0.9$ hours, $P<$ 0.001). Also, the total dose of morphine consumed was significantly lower in the naloxone group $(13 \pm 0.8 \mathrm{mg})$ than the bupivacaine group $(26.4 \pm 1.1 \mathrm{mg}, P<0.001)$ (Table 2).

In group $\mathrm{B}$, one case developed bradypnea and two complained of vomiting, while in the naloxone group, only one case developed bradypnea and one complained from postoperative vomiting. The incidence of postoperative complications, including bradypnea, hypoxemia, nausea and vomiting, pruritus, or hypotension, was not significantly higher in one group than the other $(P=0.8)$ (Table 3).

Regarding postoperative quality of sleep, in the bupivacaine group, the majority of cases (50\%) had a fair quality of sleep, while $33.3 \%$ experienced a good quality of sleep and $16.7 \%$ very good sleep. But in the naloxone group, the majority (66.7\%) experienced good sleep, while $33.3 \%$ had a fair quality of postoperative sleep (Table 4).

\section{DISCUSSION}

In the present trial, we evaluate the effect of adding a

Table 2. Supplementary Opioids

\begin{tabular}{cccc}
\hline Variable & $\begin{array}{c}\text { Bupivacaine } \\
(n=30)\end{array}$ & $\begin{array}{c}\text { Bupivacaine- } \\
\text { naloxone } \\
(n=30)\end{array}$ & $P$ value \\
\hline $\begin{array}{c}\text { Time of first rescue } \\
\text { analgesia ( } h)\end{array}$ & $6.7 \pm 0.9$ & $11 \pm 0.8<0.001^{*}$ \\
$\begin{array}{c}\text { Supplementary opioids } \\
(\mathrm{mg} / \mathrm{d})\end{array}$ & $26.4 \pm 1.1$ & $13 \pm 0.8<0.001^{*}$ \\
\hline
\end{tabular}

Values are presented as mean \pm SD.

${ }^{*} P<0.05$. small dose of naloxone to bupivacaine, versus using bupivacaine alone, on the duration of IP analgesia after thoracotomy. To avoid post-thoracotomy retention of $\mathrm{se}^{-}$ cretions, atelectasis, and pneumonia, it is necessary to control postoperative pain and encourage coughing.

Intrapleural regional analgesia has been recommended as a simple technique [8], providing safe, high-quality analgesia after thoracotomy [9]. Intrapleural regional analgesia depends on local analgesic drug diffusion from the IP space to the intercostal space, resulting in an intercostal nerve block, which produces an ipsilateral somatic block of multiple thoracic dermatomes. This proposed mechanism was confirmed by Strømskag et al. [10], who studied local analgesic distribution intrapleuraly using computerized tomography and found that the IP technique can block the sympathetic chain and splanchnic nerves.

Our results showed that the naloxone group recorded prolonged pain relief postoperatively with significant prolongation of the time for the first request of rescue analgesia, in comparison to the bupivacaine group (11 \pm 0.8 hours versus $6.7 \pm 0.9$ hours, $P<0.001$, in group $\mathrm{N}$ and group $\mathrm{B}$, respectively). We suggested that a shorter duration of IP analgesia may be due to a large IP space, as in healthy human adults the two layers of the pleura have a surface area of about $0.2 \mathrm{~m}^{2}$, as well as dilution of drugs by pleural exudation and blood as the IP space is filled with approximately $10 \mathrm{ml}$ of pleural fluid, loss of drugs in the

Table 3. Postoperative Complications

\begin{tabular}{lcc}
\hline $\begin{array}{l}\text { Postoperative } \\
\text { complication }\end{array}$ & $\begin{array}{c}\text { Bupivacaine } \\
(\mathrm{n}=30)\end{array}$ & $\begin{array}{c}\text { Bupivacaine-naloxone } \\
(\mathrm{n}=30)\end{array}$ \\
\hline Bradypnea & 1 & 1 \\
Hypoxemia & 0 & 0 \\
Hypotension & 0 & 0 \\
Pruritis & 0 & 0 \\
Vomiting & 2 & 1 \\
Total (\%) & $3(10)$ & $2(6.7)$ \\
$P$ value & & 0.8 \\
\end{tabular}

Table 4. The Quality of the Sleep of the Patients at the Night Following the Surgery by Consensus Sleep Diary

\begin{tabular}{|c|c|c|c|c|c|c|c|c|c|c|}
\hline Variable & \multicolumn{5}{|c|}{ Bupivacaine $(n=30)$} & \multicolumn{5}{|c|}{ Bupivacaine-naloxone $(n=30)$} \\
\hline Quality of the sleep & Very poor & Poor & Fair & Good & Very good & Very poor & Poor & Fair & Good & Very good \\
\hline No. of patients (\%) & 0 & 0 & $15(50)$ & $10(33.3)$ & $5(16.7)$ & 0 & 0 & $10(33.3)$ & $20(66.7)$ & 0 \\
\hline$P$ value & & & & & & 0.5 & & & & \\
\hline
\end{tabular}


chest drain, and postoperative tissue edema that prevent drugs from reaching the intercostal nerves. Our results from group B show the duration of analgesia as being similar to that reported by many other studies $(4.7 \pm 1)$ [11,12]. In contrast, in the Abd El-Aziz et al. [13] study, a total of 80 pediatric patients underwent elective thoracotomy and were assigned either to receive thoracic epidural analgesia or IP analgesia. They used bupivacaine $1.5 \mathrm{mg} / \mathrm{kg}$ in $0.25 \%$ concentration, and found the time to first rescue analgesia was shorter in the IP group compared to our study $(2.7 \pm 0.9)$ as they used a lower drug concentration.

Low doses of naloxone may release endorphins or displace them from receptor sites. This phenomenon may elucidate the significant prolongation of the naloxone-induced sensory block in our study [14]. But as we have not studied the pharmacokinetics of naloxone when injected intrapleuraly, our observation was not clear. However, we are interested in finding a clear explanation for this through further studies. We also reported higher VAS scores in the naloxone group after $12 \mathrm{~h}$, while the bupivacaine group was pain-free by this time as those patients were under the effect of rescue analgesia; bupivacaine decreases VAS scores for an average of $8 \mathrm{~h}$ only.

Naloxone, which gains its popularity as an opioid antagonist, might induce an analgesic effect. Few studies have been published on the use of naloxone for pain relief when added in low dose with LAs in various nerve blockades $[5,6,11]$. Naloxone produces a dose-dependent pain response; in the rat model, small doses of naloxone produced paradoxical analgesia, while larger doses resulted in hyperalgesia. Clinically, a low dose of naloxone enhanced morphine analgesia in an emergency intraoperative setting [15]. However, in the future, a larger sample size with variations in the dose of naloxone is needed to determine the optimal amount for prolongation of sensory block.

Movafegh et al. [16] studied the effect of adding an ultra-low dose of naloxone to lidocaine for axillary blockade, and reported that adding naloxone to the lidocaine solution prolongs sensory and motor blockade, with a significant increase in the duration of time to the first postoperative pain felt in the naloxone group. Marashi et al. [5] studied adding naloxone in low dose to LAs versus using naloxone in low dose with fentanyl and LAs in the supraclavicular brachial plexus block. They concluded that naloxone plus bupivacaine prolonged the duration of neural blockade, which leads to a significant increase in sensory and motor block time. Also, the addition of a low dose of naloxone with fentanyl enhanced its opioid effects rather than having an antagonist effect. They have thus combined naloxone with a narcotic drug, while our main idea was to use naloxone alone as an adjuvant to LA drugs.

Al-Shukaili et al. [17] added an ultra-low dose of naloxone to bupivacaine in the supraclavicular brachial plexus block, and allocated patients into either a control group that received $20 \mathrm{ml}$ bupivacaine with $3 \mathrm{ml}$ normal saline (group B) or a study group that received $20 \mathrm{ml}$ bupivacaine with $100 \mu \mathrm{g}$ of naloxone in $3 \mathrm{ml}$ saline (group BN). They reported that naloxone produces an increase in the duration of sensory block by about $3 \mathrm{~h}$. Recovery of sensory block was slower in group BN (15.6 $\pm 3.2 \mathrm{~h})$ compared to group B $(13.3 \pm 2.4 \mathrm{~h} ; P<0.001)$.

Ezz and Elkala [6] added an ultra-low-dose of naloxone to fentanyl and lidocaine, versus fentanyl and lidocaine alone, for peribulbar anesthesia. They found prolongation in the duration of postoperative analgesia in patients who received naloxone, as an ultra-low-dose of naloxone combined with an opioid can improve its analgesic efficacy.

In the current study, the total dose of morphine consumed was significantly lower in the naloxone group in comparison to the bupivacaine group, which confirms the previous idea that administration of low doses of the opioid antagonist naloxone results in analgesia or enhances, rather than attenuates, the analgesic effects of morphine or other opioid agonists [18].

In agreement with our finding, Marashi et al. [5] showed that the patients in group receiving bupivacaine only, in the supraclavicular brachial plexus block, consumed more morphine than those in the naloxone groups $(P<0.05 ; 28.2 \pm 10 \mathrm{mg}$ vs. $22.2 \pm 4 \mathrm{mg})$. On the other hand, Al-Shukaili et al. [17] found no difference between the two groups, naloxone-bupivacaine and bupivacaine alone, in postoperative analgesia requirements. This difference between their results and ours may be explained by the differences in surgical procedures used in the two studies. Also, Tobias et al. [19] found that 8 of the 14 children (57\%) who received IP analgesia for post-thoracotomy pain required no postoperative rescue analgesia in the first $24 \mathrm{~h}$. Their explanation for this difference was an age-related difference in pleural permeability.

Incidence of postoperative complications, including bradypnea, hypoxemia, nausea and vomiting, pruritus, or hypotension, was not significantly increased in one group 
in comparison with the other. Hamann et al. [20] also injected low doses of intrathecal naloxone and found that there were no signs of adverse drug toxicity or hemodynamic compromise in the naloxone group.

Our results showed that the naloxone group recorded prolonged pain relief postoperatively with significant prolongation in the time before the first request for rescue analgesia in comparison to the bupivacaine group. We used this ultra-low dose of naloxone (100 ng) since it was safely used in previous studies $[5,6]$, and depending on the previous idea that naloxone produces a dose-dependent pain response.

Unrelieved acute pain may have a significant impact on sleep, as observed in our study. In the bupivacaine group, the majority of cases (50\%) had a fair quality of sleep, while in the naloxone group, the majority (66.7\%) experienced good sleep. But in our study, we did not correlate between quality of sleep and pain severity, which is considered a limitation of this study. Similarly, Strassels et al. [21] reported that acute pain substantially impaired patients' sleep during the postoperative period.

Limitations of our study also include the small sample size involved, lack of both measurements of serum bupivacaine levels and gaseous exchange parameters, and injection in the form of a single bolus for IP regional analgesia, which was chosen for the sake of ensuring accurate detection of the length of the naloxone sensory blockade. Continuous infusion is recommended instead. More studies comparing different doses of naloxone and different concentrations of LAs are also recommended.

We concluded that the addition of a small dose of naloxone to bupivacaine in IP regional analgesia leads to prolonged pain relief after thoracotomy, with a delayed request for rescue analgesia, without any significant adverse effects.

\section{CONFLICT OF INTEREST}

No potential conflict of interest relevant to this article was reported.

\section{REFERENCES}

1. Takamori S, Yoshida S, Hayashi A, Matsuo T, Mitsuoka M, Shirouzu K. Intraoperative intercostal nerve blockade for postthoracotomy pain. Ann Thorac Surg 2002; 74: 338-41.
2. Schneider RF, Villamena PC, Harvey J, Surick BG, Surick IW, Beattie EJ. Lack of efficacy of intrapleural bupivacaine for postoperative analgesia following thoracotomy. Chest 1993; 103: 414-6.

3. Okmen K, Okmen BM, Uysal S. Serratus Anterior Plane (SAP) block used for thoracotomy analgesia: a case report. Korean J Pain 2016; 29: 189-92.

4. Mathur SK, Jain S, Agrawal D, Ranjan P, Jain A. Comparison of interpleural and thoracic epidural bupivacaine with buprenorphine for post-thoracotomy analgesia. Indian J Anaesth 2008; 52: 432-9.

5. Marashi SM, Sharifnia HR, Azimaraghi O, Aghajani Y, Barzin G, Movafegh A. Naloxone added to bupivacaine or bupivacaine-fentanyl prolongs motor and sensory block during supraclavicular brachial plexus blockade: a randomized clinical trial. Acta Anaesthesiol Scand 2015; 59: 921-7.

6. Ezz HA, Elkala RS. Ultra-low-dose naloxone added to fentanyl and lidocaine for peribulbar anesthesia: a randomized controlled trial. Egypt J Anaesth 2015; 31: 161-5.

7. Carney CE, Buysse DJ, Ancoli-lsrael S, Edinger JD, Krystal $A D$, Lichstein $K L$, et al. The consensus sleep diary: standardizing prospective sleep self-monitoring. Sleep 2012; 35: 287-302.

8. Gilani N, Kazemnejad A, Zayeri F, Kazempour Dizaji M, Dabir S. Effects of interpleural morphine on severity of postthoracotomy pain. Scimetr 2014; 2: e87373.

9. Dravid RM, Paul RE. Interpleural block: part 1. Anaesthesia 2007; 62: 1039-49.

10. Strømskag KE, Hauge O, Steen PA. Distribution of local anesthetics injected into the interpleural space, studied by computerized tomography. Acta Anaesthesiol Scand 1990; 34: $323-6$.

11. Al-Khayat HS, Patwari A, El-Khatib MS, Osman H, Naguib K. Intrapleural bupivacaine analgesia: bolus versus continuous infusion technique for postoperative pain relief in children. Indian J Anaesth 2008; 52: 404-11.

12. Greif R, Wasinger T, Reiter K, Chwala M, Neumark J. Pleural bupivacaine for pain treatment after nephrectomy. Anesth Analg 1999; 89: 440-3.

13. Abd El-Aziz MA, Elnakera AM, Salah AA. Post-thoracotomy pain relief in pediatric patients epidural versus inter-pleural analgesia. Res Opin Anesth Intensive Care 2015; 2: 132-9.

14. Gan TJ, Ginsberg B, Glass PS, Fortney J, Jhaveri R, Perno R. Opioid-sparing effects of a low-dose infusion of naloxone in patient-administered morphine sulfate. Anesthesiology 1997; 87: 1075-81.

15. Levine JD, Gordon NC, Fields HL. Naloxone dose dependently produces analgesia and hyperalgesia in postoperative pain. Nature 1979; 278: 740-1.

16. Movafegh A, Nouralishahi B, Sadeghi M, Nabavian O. An ultra-low dose of naloxone added to lidocaine or lidocainefentanyl mixture prolongs axillary brachial plexus blockade. 
Anesth Analg 2009; 109: 1679-83.

17. Al-Shukaili AA, AL-Mandhari KM, Younis B, Lad S, Othman A, Jose S. Ultra-low dose naloxone added to $0.5 \%$ bupivacaine significantly prolongs the duration of analgesia following supraclavicular brachial plexus block. Am J Med Case Rep 2016; 4: 336-8.

18. Crain SM, Shen KF. Ultra-low concentrations of naloxone selectively antagonize excitatory effects of morphine on sensory neurons, thereby increasing its antinociceptive potency and attenuating tolerance/dependence during chronic cotreatment. Proc Natl Acad Sci U S A 1995; 92: 10540-4.
19. Tobias JD, Martin LD, Oakes L, Rao B, Wetzel RC. Postoperative analgesia following thoracotomy in children: interpleural catheters. J Pediatr Surg 1993; 28: 1466-70.

20. Hamann S, Sloan PA, Witt W. Low-dose intrathecal naloxone to enhance intrathecal morphine analgesia: a case report. J Opioid Manag 2008; 4: 251-4.

21. Strassels SA, McNicol E, Wagner AK, Rogers WH, Gouveia WA, Carr DB. Persistent postoperative pain, health-related quality of life, and functioning 1 month after hospital discharge. Acute Pain 2004; 6: 95-104. 